\section{$\$$ Research Square}

\title{
The association between dietary inflammatory index (DII) and obesity indices in university students in Tehran
}

\section{Narges Khamoush Cheshm}

Science And Reseach Branch Islamic Azad University

\section{Asal Ataie-Jafari}

Department Of Nutrition, Science And Reseach Brabch, Islamic Azad University,Tehran

Shahryar Eghtesadi ( $\nabla$ segtesadi@gmail.com )

Science And Reseach Branch Islamic Azad University

\section{Aniseh Nikravan}

Department of Health Services Administration, Science and Research Branch, Islamic Azad University, Tehran

\section{Nitin Shivappa}

University of South Carolina Cancer Prevention and Control Program

James R Hebert

University of South Carolina Cancer Prevention and Control Program

\section{Research}

Keywords: dietary inflammatory index, obesity, fat mass, anthropometric.

Posted Date: October 2nd, 2020

DOl: https://doi.org/10.21203/rs.3.rs-84928/v1

License: (c) (i) This work is licensed under a Creative Commons Attribution 4.0 International License.

Read Full License 
The association between dietary inflammatory index (DII) and obesity indices in university students in Tehran

Narges Khamoush Cheshm ${ }^{1}$, Asal Ataie-Jafari ${ }^{\text {*** }}$, Shahryar Eghtesadi ${ }^{* *}$, Aniseh Nikravan ${ }^{2}$, Nitin Shivappa ${ }^{3,4,5}$, James R. Hebert ${ }^{3,4,5}$

${ }^{1}$ Department of Nutrition, Science and Research Branch, Islamic Azad University, Tehran, Iran.

${ }^{2}$ Department of Health Services Administration, Science and Research Branch, Islamic Azad University, Tehran, Iran.

${ }^{3}$ Cancer Prevention and Control Program, University of South Carolina, Columbia, SC 29208, USA.

${ }^{4}$ Department of Epidemiology and Biostatistics, Arnold School of Public Health, University of South Carolina, Columbia, SC 29208, USA.

${ }^{5}$ Department of Nutrition, Connecting Health Innovations LLC, Columbia, SC 29201, USA.

*Correspondence to Shahryar Eghtesadi, Ph.D. Department of Nutrition, Science and Research Branch, Islamic Azad University, Tehran, Iran. Email: segtesadi@ gmail.com

**Co-Correspondence to Asal Ataie-Jafari, Ph.D. Department of Nutrition, Science and Research Branch, Islamic Azad University, Tehran, Iran. Email: asal_ataie2003@yahoo.com 


\section{ABSTRACT}

Background: Obesity, a major cause of low-grade chronic inflammation, is a major public health issue globally. Inflammation arising from obesity affects organs, such as kidney and liver, and is associated with chronic diseases such as diabetes and cardiovascular disease. We aimed to investigate the association between the dietary inflammatory index (DII ${ }^{\circledR}$ ) and obesity indices in university students.

Methods: This cross-sectional study included 361 college students. DII scores were calculated from dietary data collected using a semi-quantitative food frequency questionnaire (FFQ). Anthropometric measurements were taken, and body composition analyzed by bioelectrical impedance analysis (BIA).

Results: The mean age of the 361 students was $21.94 \pm 4.04$ years and $53.2 \%$ were female The mean DII was $1.26 \pm 1.08$. Among participants, $36.8 \%$ were overweight and obese and $9.1 \%$ suffered from abdominal obesity. The DII score was not associated with body weight, body mass index (BMI), body fat, waist circumference or visceral fat (both unadjusted and after adjustment for covariates).

Conclusion: The present study showed no association between the DII and obesity indices given the proven effects of both the DII and obesity on health indicators, it would be a good strategy to conduct studies with prospective designs to determine the exact effects of DII on obesity indicators.

Key words: dietary inflammatory index, obesity, fat mass, anthropometric. 


\section{INTRODUCTION}

Obesity is one of the main public health issues in both developed and developing countries. The prevalence of overweight and obesity in adults was reported at $39 \%$ and $13 \%$; respectively, by WHO in $2016(1,2)$. The prevalence of overweight and obesity in Middle Eastern countries is $54 \%$ among women and $31 \%$ among men, and can be traced to the deaths of 150,000 people in these countries $(3,4)$. More than half $(63.2 \%)$ of individuals aged 15-65 years old were reported to be overweight and obese according to the first national study and the study of glucose and lipids in Tehran. In another report, the overall prevalence of obesity in people aged 25-64 years in Iran was mentioned as $22.3 \%(2,3,5)$.

Obesity is caused by the accumulation of fat in the body, and although it is partly genetically determined, environmental factors such as socioeconomic status, gender, marital status, physical activity, level of education, and dietary factors also exert an important influence on obesity prevalence worldwide (3).

The concentration of systemic inflammation biomarkers such as CRP, TNF $\alpha$, IL8 and IL6 increases in obesity, which is why it is known as a low degree of chronic inflammation (6). Inflammation caused by obesity has metabolic effects on several organs, including adipose tissue, liver, muscle, pancreas and brain, and these conditions are associated with metabolic diseases such as hyperglycemia, hypertension and dyslipidemia. Metabolic differences can be seen depending on the location of the fat cells. For example, excessive fat accumulation in visceral adipose tissue is associated with higher health risks than subcutaneous fat accumulation $(1,7)$.

Numerous studies have shown a positive association between inflammatory markers and obesity indices. One study found a positive relationship between CRP and waist circumference and waist-to-height ratio (8). Recently, there has been a hypothesis that obesity can be the result of low levels of chronic inflammation. Therefore, there is a mutual relationship between inflammation and obesity (9).

Diet is another environmental factor that has been proven to have an important effect on systemic inflammation. The results show that high consumption of whole grains, olive oil, fruits, vegetables and fish, and low consumption of red meat and low to moderate consumption of wine (Mediterranean diet pattern) is associated with a decrease in inflammation. In contrast, the Western diet (rich in refined grains, red meat, high-fat dairy products) is associated with high levels of inflammatory biomarkers $(10,11)$. By contrast, fiber, complex carbohydrates, omega-3 fatty acids, vitamin $\mathrm{C}$, vitamin $\mathrm{E}$, magnesium and beta-carotene have anti-inflammatory effects, while saturated fatty acids and sugar have inflammatory effects (12).

The dietary inflammation index (DII ${ }^{\circledR}$ ) was designed to assess the inflammatory potential of the diet, first was described by Nitin Shivappa et al. In 2009 and updated in 2014 (13). The DII is used to assess the inflammatory potential of the diet based on the inflammatory and antiinflammatory properties of specific foods, spices, macronutrients, micronutrients and flavonoids (13).

Various studies have been performed on the relationship between DII and obesity indices. In two observational studies, a significant relationship was observed between DII score and anthropometric indices in adults $(1,14)$. Weight gain and overweight showed a positive 
relationship with high levels of DII score in a prospective study (10). Although this relationship was not observed in obese and normal teachers in another study (15). Another prospective study also found a direct relationship between DII and weight, BMI, waist-to-hip circumference, and fat percentage (16). However, in another study of college students, no significant relationship was found between DII and the above items (17).

Due to the different results that have been observed in various studies and few research in Iran, especially in the relationship between DII and obesity indices and body fat percentage, this study aimed to investigate the relationship between DII and obesity indices in university students in Tehran.

\section{MATERIALS \& METHODS}

This was a cross-sectional study. The study protocol was approved by the Ethics Committee of the Islamic Azad University, Science and Research Branch with the ID: IR.IAU.SRB.REC.1398.080

A total of 381 healthy single students, aged 18-35 years, studying at the Islamic Azad University of Science and Research Branch were selected using two-stage random sampling method. The study inclusion criteria were as follows: no history of chronic diseases such as diabetes, liver and kidney diseases, not having any special diet such as a vegetarian and weight-loss diets. The participants who consumed less than $1000 \mathrm{kcal}$ per day (according to the food frequency questionnaire) were excluded from the study and the final number of participants included in the study was 361 .

Dietary intake was evaluated by a 147-item FFQ, the validity and reliability of which were established in previous studies (18). The participants were asked to report their food consumption frequencies on a daily, weekly, monthly or yearly basis. Food quantities reported were converted to grams per day using household measure. Then, each food item, according to the prescribed protocol, was analyzed for content of energy and the other nutrients using Nutritionist IV software (version 3.5.2, N-Squared Computing, Salem, OR, USA).

\section{Calculation of dietary inflammatory index (DII)}

The DII is actually a scoring algorithm based on an extensive review of the literature (1950 to 2010) linking 1943 articles to food parameters including various macronutrients and micronutrients. Each food parameter was scored according to whether it increased $(+1)$, decreased (-1) or had no effect (0) on the six inflammatory indices IL-1 $\beta$, IL-6, C-reactive protein (CRP) and tumor necrosis factor-alpha (TNF- $\alpha)$. The DII is calculated based on the intake of 45 nutritional parameters whose inflammatory score, mean and SD of the global intake of each nutritional parameter are calculated(13). 
In the DII score calculation process, first, intakes of each of 45 food parameters were obtained from the FFQ. Then, the values obtained for each variable were subtracted from the corresponding mean global intake and divided by the global SD to obtain the z-score. To minimize the effect of "right skewness", the z-score was converted to a portion (value 0 to 1 ) and centered by the by each by 2 and subtracting 1 . In the next step, the numbers obtained for each of the food parameters were multiplied by the corresponding inflammatory score, and then the inflammation score of all of the food parameters were summed to obtain the total inflammatory score for each person. A higher (more positive) DII score indicates a more pro-inflammatory diet and lower scores represent an anti-inflammatory diet (13). The theoretical minimum of the DII score is -8.87 , while the maximum score is +7.98 .

In the present study, 34 dietary food parameters were used to calculate the DII including energy, protein, total fat, saturated fatty acids (SFA), MUFA, PUFA, trans fatty acids, omega 3 and omega 6 fatty acids, cholesterol, carbohydrates, fiber, caffeine, Vitamin A, beta carotene, thiamine, riboflavin, niacin, vitamin B6, folate, vitamin B12, vitamin $\mathrm{C}$, vitamin $\mathrm{D}$, vitamin $\mathrm{E}$, iron, magnesium, selenium, zinc, tea, garlic, onion, pepper, turmeric and thyme. Because the FFQ and N4 software were not able to collect information on other dietary data (Eugenol, saffron, Flavan-3-ol, Flavones, Flavonols, Flavonones, Anthocyanidins, Isoflavones, Ginger and Rosemary) required calculating DII, this index was calculated by 34 dietary parameters. Alcohol was not reported in this largely abstinent group.

\section{Anthropometric measurements}

The anthropometric assessments were performed using the techniques provided by the World Health Organization. The standing body height (stature) was recorded using a calibrated stadiometer (Seca206, Germany) with an accuracy of $0.1 \mathrm{~cm}$ with the subject standing straight, without shoes. Weight, body mass index (BMI), percent body fat (PBF), and lean body mass (LBM) were also measured by body impedance analysis (Omron, BF511, Kyoto, Japan) (19). Waist circumference (WC) was measured midway between the lowest ribs margin and the iliac crest at the level of the umbilicus and at the end of normal expiration. Measurements were performed using non-stretchable tape, without any pressure on it with the least count $0 / 1 \mathrm{~cm}$. Waist to height ratio (WHtR) was calculated by dividing the waist circumference $(\mathrm{cm})$ by the height $(\mathrm{cm})$ of subjects.

\section{Evaluation of other variables}

A general questionnaire was used to collect the additional variables including age, sex, education level, socioeconomic status and drug use (including supplements). The data related to physical activity were collected using the International Physical Activity Questionnaire (IPAQ) (20). 
Participants were categorized based on tertiles of dietary inflammatory index. One-way ANOVA and Chi-square test were used to determine the existence of a significant correlation between quantitative and qualitative variables and tertiles of DII, respectively. Linear regression was used to see whether there is a correlation between DII score and anthropometric indices such as BMI, WC, PBF, LBM, and visceral body fat. In this modeling technique, dependent variables were considered quantitative. Logistic regression models were also used to see whether there is a correlation between DII, overweight, obesity and abdominal obesity. In this model, unlike linear regression model, the dependent variable was considered collectively. Confounders such as age, sex and other variables that could negatively affect the afore-mentioned correlations were controlled and adjusted. In all multiple models, the third tertile of DII was considered as the reference. All statistical analysis was performed using SPSS 24, IBM Corporation, Armonk, NY, USA) and $\alpha=0.05$ ( $\mathrm{P}<0.05)$ was set as the nominal level for statistical significance.

\section{RESULTS}

A total of 361 participants with a mean age of $21.94 \pm 4 / 04$ included in the study. Over half, 192 subjects $(53.2 \%)$. The overall mean of DII was $1.26 \pm 1.08$ The DII score ranged from 2.22 to 4.15 in the study participants. Over $1 / 3$ (133) participants $(36.8 \%)$ were overweight or obese and $33(9.1 \%)$ suffered from abdominal obesity. Table 1 shows the basic information of the participants. The results of this study showed that education level and severity of physical activity were significantly correlated with DII score ( $\mathrm{P}=0.02$ and 0.03 , respectively). Our results also showed that multivitamin and omega 3 supplements intake is significantly correlated with DII score $(\mathrm{P}=0.001$ and 0.03 , respectively).

Higher DII score was related to greater fat intake (gr/day) $(\mathrm{P}=0.03)$. Our results also showed that an increase in DII led to increase of energy intake from fat $(\mathrm{P}<0.001)$ and decrease of energy intake from carbohydrate and protein $(\mathrm{P}<0.001$ and $\mathrm{P}=0.01$, respectively). Also, with increasing DII, there was a significant difference between the average intake of saturated fatty acids, vitamin A, $\beta$-carotene, vitamin $\mathrm{C}$, vitamin B6, magnesium, garlic and pepper in the tertiles od DII ( $\mathrm{P}<0.05)$. With increasing DII score, the average intake of saturated fatty acids increased and the average intake of vitamin $\mathrm{A}, \beta$-carotene, vitamin $\mathrm{C}$, vitamin B6, magnesium, garlic and pepper decreased $(\mathrm{P}<0.05)$, (Table 2).

Table 3 shows the mean of anthropometric indices across DII tertiles. There were no significant differences between crude and adjusted results with respect to all anthropometric indices at different DII levels as shown in Table 3.

Standardized regression coefficients (B) for obesity indices across tertiles of DII are provided in Table 4. The relationship between DII and obesity indices was investigated using simple and multiple linear regression models. The third tertile was used as the reference and the 
other two tertiles were compared with it. In the crude model, only the DII index was assessed and in the adjusted model analyses were carried based on confounding variables including sex, age, physical activity, economic status, supplementation and energy intake. There was no significant association between obesity indices such as weight, BMI, WC and WHtR as well as anthropometric indices such as PBF, LBM and visceral fat and DII in both crude and adjusted models.

Odds ratios (ORs) for for obesity, abdominal obesity and overweight across tertiles of DII are provided in Table 5. Logistic regression was used in this relationship. The third tertile was used as the reference and the other two tertiles were compared with it. In the crude model, only the DII index was assessed and in the adjusted model analyses were carried based on confounding variables including sex, age, physical activity, economic status, supplementation and energy intake. There was no significant difference between DII and overweight, obesity and abdominal obesity in both crude and adjusted models.

\section{DISCUSSION}

In the present study, there was a significant inverse association between DII and level of education. In other words, an increase in education level led to a decline in the DII score. The results of the present study are in line with previous research conducted in Iran showing that there was an inverse association between DII and higher education level (21). Shivappa et al. conducted a study on 20,823 Italian adults, and found a positive correlation between DII and education level (22). The results of a relevant study on 329 African-Americans with a mean age of 55 years showed no significant association between DII and education level (23). The inverse relationship between education and DII may be due to the greater awareness of more educated people about the beneficial or harmful effects of foods.

Comparing the intensity of physical activity in different DII tertiles revealed a significant difference between the groups. Silva Oliveira et al. conducted a study on 3151 university graduates, and found that there was a significant correlation between DII and physical activity (24), which are consistent with our results. Also, Varkaneh et al. conducted a study on 198 women with a mean age of 33.4 years who referred to medical centers, and the results showed that there was a significant relationship between DII and physical activity (4). The present study showed that people with moderate to vigorous physical activity had a lower DII score. Therefore, it appears that people with more vigorous physical activity usually have more healthy and nutritious diets and, consequently, a lower DII score.

In the present study no association was observed between the DII and energy intake. In a study of 110 students, Kim et al., found no significant association between DII and energy intake (17). However, in the study conducted by Mazidi et al. there was a positive correlation between 
DII and energy intake (25). Similarly, in another study conducted in Italy, Shivappa et al. found a significant correlation between DII and energy intake (22).

The present study showed that higher fat intake was associated with a higher DII score. Also, a lower percentage of energy intake from carbohydrates and protein is associated with a higher DII score. In a study conducted by Kim et al. on 110 students, no association was found between protein and carbohydrate intake and DII, but there was a direct relationship between fat intake and DII (17). Cora et al. conducted a study on 599 participants with a mean age of 20 years, and the results demonstrated that there was a significant relationship between energy, carbohydrate and protein intake and DII, but it no was not correlated with total fat intake (7). The discrepancies observed in different studies may be due to the sample size differences or the effect of physical activity on daily energy intake. For example, in the present study, the majority of male participants had moderate to vigorous physical activity and therefore had higher energy intakes.

In the present study, no significant association was observed between obesity indices and DII. In line with the current study, in a study aimed to investigate the association between DII with CRP and metabolic syndrome in 1712 Chinese adults aged 18-75 years, no significant association was observed between DII and BMI (26). Also, another study conducted on 532 European adults to examine the association between DII and inflammatory markers, no significant relationship was found between the DII and BMI (27). Moe Sun et al. conducted on overweight and normal teachers, and the results showed that no significant association was found between DII and overweight (15). However, in a study conducted in a large Italian population people, Shivappa et al. found an inverse association between DII and BMI (22). Also, in their study, Varkaneh et al., found a significant relationship between DII and BMI and waist circumference, but was not correlated with general obesity (4). In a cross-sectional study performed on 606 East Azerbaijan participants with a mean age of 42 years, there was no significant association between DII and waist circumference (28).

In a similar study of 503 Indonesian people aged 19-56 years, Mohammad et al. investigated the association between DII, weight, blood pressure, lipid profile and leptin level. The results showed no significant correlation between DII, weight, waist circumference and body fat percentage. This correlation remained non-significant even after adjusting for confounding factors (29).

Kim et al. (2018) conducted a study of 110 students to investigate the association between DII and glycemic index, and they found that there was no significant relationship between DII and weight, BMI, waist circumference and fat percentage (17). Also, Camargo et al. (2017) conducted a study on 90 overweight men and women with sedentary lifestyle, aimed to investigate the association between DII and heart risk factors, and the results indicated that there was no significant association between DII and weight, waist circumference, BMI, Obesity, overweight and body fat percentage (30). In their study, Cora et al., evaluated the association of 
DII with bone health and body composition in the young population, and the results showed no association between DII and BMI, fat percentage, muscle percentage and visceral fat, before and after adjusting for confounding factors (7). However, in a prospective study of Alam et al. performed on 651 men, there was a direct and significant association between DII and weight, waist-to-hip ratio (WHR) and body fat percentage (16).

Discrepancies in the results from studies may be due to differences in the number of participants, race of the subjects, the number of dietary parameters used to compute the DII score, different food intake data collection methods, the impact of confounding factors, and age range of subjects.

The study of healthy young populations who are rarely investigated in relevant studies in Iran can be considered as one of the strengths of the present study. Also, the study of the relationship between DII with body fat percentage and muscle percentage, has rarely been investigated in Iran and was also a feature of the present study. Study of both genders (though similar studies are mostly focused on females in Iran) and the availability of confounding factors that made it easier to apply the adjustment in the modified model were also among the advantages of this study. Despite its strengths, this study has a number of weaknesses including small sample size, dietary assessments that are subject to recall another biases, and its crosssectional design. Future studies should be conducted and overcome these weaknesses, especially larger perspective studies in unique populations that may be at higher risk of metabolic obesity (31-33).

\section{CONCLUSION}

This study showed no significant association between DII and anthropometric indices such as weight, BMI, waist circumference, WHR, body fat percentage, muscle mass percentage and visceral fat. Taking into account the effect of diet on overall health and inflammation, more welldesigned prospective studies as well as clinical trials are warranted to discover the effect of diet on health indices, including the prevention of overweight and obesity.

\section{List of abbreviations}

WHO: World Health Organization

BMI: Body Mass Index

WC: Waist circumference

WhtR: Waist-to-Height Ratio

CVD: Chronic Vascular Disease

CRP:C-reactive Protein 
TNF $\alpha$ : Tumor Necrosis Factor alpha

IL6: Interleukin 6

DII: Dietary Inflammatory Index

BFM: Body Fat Mass

VSF: Visceral Fat

BIA: Bio impedance Analysis

MUFA: Monounsaturated fatty acids

SFA: Saturated Fatty Acid

E-DII: energy adjusted-DII

IPAQ: International Physical Activity Questionnaire

FFQ: Food Frequency Questionnaire

USDA: United States Department of Agriculture

\section{Declarations}

\section{Ethics approval and consent to participate}

The study protocol was approved by the Ethics Committee of the Islamic Azad University, Science and Research Branch with the ID: IR.IAU.SRB.REC.1398.080. Written informed consent was obtained from all participants.

\section{Consent for publication}

Not applicable.

\section{Availability of data and materials}

The datasets generated and analyzed during the current study are not publicly available, due to institutional policy, but may be requested directly from the corresponding author.

\section{Competing interests}


The authors declare that they have no competing interests.

\title{
Funding
}

This research received no specific Grant from any funding agency in the public, commercial, or not-for-profit sectors.

\section{Authors' contributions}

NKH, AA-J and SHE designed and conceived the research. NKH recruited participants and collected data. NSH, JH and AN analyzed the data and interpreted the results. SHE and AA drafted the manuscript. All authors read and approved the final manuscript.

\section{Acknowledgements}

The authors appreciate students who participated in this study.

\section{Authors' information}

\begin{abstract}
Affiliations
Department of Nutrition, Science and Research Branch, Islamic Azad University, Tehran, Iran.
\end{abstract}

Narges Khamoush Cheshm, Asal Ataie-Jafari, Shahryar Eghtesadi

Department of Health Services Administration, Science and Research Branch, Islamic Azad University, Tehran, Iran.

Aniseh Nikravan

Cancer Prevention and Control Program, University of South Carolina, Columbia, SC 29208, USA.

Nitin Shivappa, James R. Hebert 
Department of Epidemiology and Biostatistics, Arnold School of Public Health, University of South Carolina, Columbia, SC 29208, USA.

Nitin Shivappa, James R. Hebert

Department of Nutrition, Connecting Health Innovations LLC, Columbia, SC 29201, USA.

Nitin Shivappa, James R. Hebert 
Table 1. Characteristics of study participants according to Tertiles (T) of the DII.

\begin{tabular}{|c|c|c|c|c|c|c|c|c|c|c|}
\hline \multirow{2}{*}{\multicolumn{2}{|c|}{ Characteristic }} & \multicolumn{2}{|c|}{ DII Score Tertile1 } & \multicolumn{2}{|c|}{$\begin{array}{c}\text { DII Score } \\
\text { Tertile2 } \\
\end{array}$} & \multicolumn{2}{|c|}{ DII Score Tertile3 } & \multirow{2}{*}{\multicolumn{2}{|c|}{ All (361) }} & \multirow[b]{2}{*}{ P-value } \\
\hline & & \multicolumn{2}{|c|}{$\begin{array}{c}\left(-2.22 \_0.78\right) \\
(n=120)\end{array}$} & \multicolumn{2}{|c|}{$\begin{array}{c}\left(0.79 \_1.72\right) \\
(n=121)\end{array}$} & \multicolumn{2}{|c|}{$\begin{array}{c}\left(1.73 \_4.15\right) \\
(n=120)\end{array}$} & & & \\
\hline \multicolumn{2}{|c|}{ Continuous Variables } & mean & SD & mean & SD & mean & SD & mean & SD & \multirow{6}{*}{0.61} \\
\hline \multicolumn{2}{|c|}{ Age (years) } & 22.32 & 4 & 22.12 & 4.33 & 21.38 & 3.74 & 21.94 & 4.04 & \\
\hline \multicolumn{2}{|c|}{ Height $(\mathrm{cm})$} & 168.62 & 10.03 & 169.16 & 9.37 & 168.11 & 9.51 & 168.63 & 9.62 & \\
\hline \multicolumn{2}{|c|}{ Categorical Variables } & $\mathrm{N}$ & $\%$ & $\mathrm{~N}$ & $\%$ & $\mathrm{~N}$ & $\%$ & $\mathrm{~N}$ & $\%$ & \\
\hline \multirow{2}{*}{ Sex } & male & 57 & 15.8 & 60 & 16.6 & 52 & 14.4 & 169 & 46.8 & \\
\hline & female & 63 & 17.5 & 61 & 16.9 & 68 & 18.8 & 192 & 53.2 & \\
\hline \multirow{3}{*}{$\begin{array}{c}\text { Educational } \\
\text { level }\end{array}$} & bachelor & 91 & 25.2 & 100 & 27.7 & 109 & 30.2 & 300 & 83.1 & \multirow{3}{*}{$0.02^{*}$} \\
\hline & master & 25 & 6.9 & 20 & 5.5 & 9 & 2.5 & 54 & 15 & \\
\hline & $\mathrm{PhD}$ & 4 & 1.1 & 1 & 0.3 & 2 & 0.6 & 7 & 1.9 & \\
\hline \multirow{3}{*}{$\begin{array}{c}\text { Economic } \\
\text { levels }\end{array}$} & Poor & 11 & 3 & 4 & 3.9 & 14 & 3.9 & 39 & 10.8 & \multirow{3}{*}{0.88} \\
\hline & Moderate & 49 & 13.6 & 53 & 14.7 & 53 & 14.7 & 155 & 42.9 & \\
\hline & Wealthy & 60 & 16.6 & 54 & 15 & 53 & 14.7 & 167 & 46.3 & \\
\hline \multirow{3}{*}{$\begin{array}{c}\text { Physical } \\
\text { activity level }\end{array}$} & Low & 35 & 9.7 & 44 & 12.2 & 47 & 13 & 126 & 34.9 & \multirow{3}{*}{$0.03^{*}$} \\
\hline & Moderate & 42 & 11.6 & 37 & 10.2 & 50 & 13.9 & 129 & 35.7 & \\
\hline & High & 43 & 11.9 & 40 & 11.1 & 23 & 6.4 & 106 & 29.4 & \\
\hline \multirow{2}{*}{ supplements } & no & 53 & 14.7 & 65 & 18 & 69 & 19.1 & 187 & 51.8 & \multirow{2}{*}{0.1} \\
\hline & yes & 67 & 18.6 & 56 & 15.5 & 51 & 14.1 & 174 & 48.2 & \\
\hline Multi & no & 76 & 21.1 & 97 & 26.9 & 98 & 27.1 & 271 & 75.1 & \multirow{2}{*}{$0.001^{*}$} \\
\hline Vitamin & yes & 44 & 12.2 & 24 & 6.6 & 22 & 6.1 & 90 & 24.9 & \\
\hline \multirow{2}{*}{ Iron } & no & 93 & 25.8 & 93 & 25.8 & 93 & 25.8 & 279 & 77.3 & \multirow{2}{*}{0.99} \\
\hline & yes & 27 & 7.5 & 28 & 7.8 & 27 & 7.5 & 82 & 22.7 & \\
\hline \multirow{2}{*}{ Folic acid } & no & 103 & 28.5 & 113 & 31.1 & 105 & 29.1 & 321 & 88.9 & 014 \\
\hline & yes & 17 & 4.7 & 8 & 2.2 & 15 & 4.2 & 40 & 11.1 & 0.14 \\
\hline Zinc & no & 91 & 25.2 & 101 & 28 & 99 & 27.4 & 291 & 80.6 & 026 \\
\hline Zinc & yes & 29 & 8 & 20 & 5.5 & 21 & 5.8 & 70 & 19.4 & 0.20 \\
\hline Omeog 3 & no & 105 & 29.1 & 115 & 31.9 & 114 & 31.6 & 334 & 92.5 & $003 *$ \\
\hline Umegas & yes & 15 & 4.2 & 6 & 1.7 & 6 & 1.7 & 27 & 7.5 & 0.03 \\
\hline Colcium & no & 108 & 29.9 & 108 & 29.9 & 103 & 28.5 & 319 & 88.4 & 0.56 \\
\hline Calcium & yes & 12 & 3.3 & 13 & 3.6 & 17 & 4.7 & 42 & 11.6 & 0.56 \\
\hline Multi- & no & 108 & 29.9 & 111 & 30.3 & 113 & 31.3 & 332 & 92 & 040 \\
\hline Mineral & yes & 12 & 3.3 & 10 & 2.8 & 7 & 1.9 & 29 & 8 & 0.49 \\
\hline
\end{tabular}

Values are presented as mean $\pm \mathrm{SD}$, Obtained from one-way ANOVA for continuous variables and chi-square test for categorical variables. DII, dietary inflammatory index

Data are expressed by mean _ SD for continuous variables and n (\%) for categorical variables. SD: Standard deviation \# Physical activity was calculated using PAQ score which score of 1 indicates low physical activity, score of 2-4 indicates moderate physical activity, and score of 5 indicates high physical activity. ^ Socioeconomic status: The number of items 3 or less was considered poor, 4 to 6 was considered moderate and 7 to 9 was considered wealthy.

* Significant association $(\mathrm{P}<0.05)$. 
Table2. Nutrient intake according to the Tertiles of the DII score

\begin{tabular}{|c|c|c|c|c|c|c|c|c|c|}
\hline & \multirow{2}{*}{\multicolumn{2}{|c|}{$\begin{array}{c}\text { Tertile1 } \\
\left(-2.22 \_0.78\right) \\
(\mathrm{n}=120)\end{array}$}} & \multirow{2}{*}{\multicolumn{2}{|c|}{$\begin{array}{c}\text { Tertile2 } \\
\left(0.79 \_1.72\right) \\
(\mathrm{n}=121)\end{array}$}} & \multirow{2}{*}{\multicolumn{2}{|c|}{$\begin{array}{c}\text { Tertile3 } \\
\left(1.73 \_4.15\right) \\
(\mathrm{n}=120)\end{array}$}} & \multirow{2}{*}{\multicolumn{2}{|c|}{$\begin{array}{c}\text { All } \\
(\mathrm{n}=361)\end{array}$}} & \multirow[t]{3}{*}{ P-value } \\
\hline & & & & & & & & & \\
\hline & mean & SD & mean & SD & mean & SD & mean & SD & \\
\hline Energy (kcal) & 3091.3 & 1214 & 3267.3 & 1425 & 3247.7 & 1337 & 3202 & 1327.9 & 0.53 \\
\hline Carbohydrate (g) & 494.9 & 209.44 & 508.07 & 238.67 & 487.66 & 232.26 & 496.9 & 226.69 & 0.77 \\
\hline Protein (g) & 110.63 & 45.4 & 113.18 & 47.59 & 107.87 & 46.74 & 110.87 & 46.74 & 0.67 \\
\hline Total fat (g) & 89.23 & 38.6 & 100 & 49.55 & 103.91 & 49.11 & 97.72 & 46.33 & 0.03 \\
\hline Protein (\% of total kcal) & 14.42 & 2.5 & 14.1 & 2.3 & 13.45 & 2.6 & 13.99 & 2.5 & 0.01 \\
\hline $\begin{array}{l}\text { Carbohydrate (\% of total } \\
\text { kcal) }\end{array}$ & 63.62 & 6.1 & 61.89 & 6.3 & 59.34 & 8 & 61.6 & 7.1 & $0.001>$ \\
\hline Total fat (\% of total kcal) & 21.95 & 5.1 & 24 & 6 & 27.2 & 7.4 & 24.38 & 6.61 & $0.001>$ \\
\hline Cholesterol (mg) & 309.7 & 215.88 & 314.49 & 208.23 & 326.48 & 263.89 & 316.88 & 230.06 & 0.84 \\
\hline Saturated fatty acid (g) & 25.94 & 11 & 31.48 & 16.8 & 32.22 & 16.6 & 29.88 & 15.36 & 0.002 \\
\hline $\begin{array}{l}\text { Mono-unsaturated fatty acid } \\
\text { (g) }\end{array}$ & 29.32 & 13.1 & 31.68 & 16.5 & 31.72 & 14.1 & 30.9 & 14.7 & 0.35 \\
\hline Poly-unsaturated fatty acid (g) & 17.98 & 8.9 & 19.35 & 11.1 & 19.3 & 9.2 & 18.8 & 9.8 & 0.47 \\
\hline Omega3 (g) & 1.24 & 0.7 & 1.37 & 0.9 & 1.35 & 0.8 & 1.3 & 0.8 & 0.19 \\
\hline Omega6 (g) & 14.92 & 8 & 16.31 & 9.6 & 16.55 & 8.3 & 15.9 & 8.7 & 0.24 \\
\hline Fiber $(g)$ & 59.84 & 31 & 59.91 & 33.3 & 56.7 & 33.8 & 58.8 & 34.1 & 0.7 \\
\hline Beta carotene $(\mu \mathrm{g})$ & 8677.84 & 6251.2 & 4724.3 & 3366.6 & 2854.91 & 2071.7 & 5417 & 4899.8 & $0.0001>$ \\
\hline Vitamin A $\left(\mathbf{R E}^{*}\right)$ & 1101.06 & 658 & 801.27 & 562 & 266.25 & 352.5 & 822.8 & 580.8 & $0.0001>$ \\
\hline Vitamin C (mg) & 381.54 & 272.1 & 287.64 & 254.1 & 180.98 & 19 & 283.4 & 258.9 & $0.0001>$ \\
\hline Vitamin D $(\mu \mathrm{g})$ & 2.94 & 2.4 & 3 & 2.4 & 2.43 & 1.8 & 2.79 & 2.29 & 0.1 \\
\hline Vitamin E (mg) & 15.79 & 7.7 & 14.74 & 8.8 & 13.87 & 8.1 & 14.79 & 8.27 & 0.19 \\
\hline Thiamine (mg) & 2.65 & 1.1 & 2.85 & 1.4 & 2.94 & 1.4 & 2.81 & 1.29 & 0.19 \\
\hline Riboflavin (mg) & 2.74 & 1.2 & 2.8 & 1.4 & 2.48 & 1.1 & 2.67 & 1.28 & 0.12 \\
\hline Niacin (mg) & 33.98 & 14.7 & 34.07 & 15.9 & 32.22 & 15.6 & 33.43 & 15.45 & 0.58 \\
\hline Vitamin B6 (mg) & 2.85 & 1.2 & 2.72 & 1.2 & 2.4 & 1.1 & 2.66 & 1.22 & 0.01 \\
\hline Folate (mg) & 732 & 278.8 & 728.03 & 294.1 & 762.55 & 350 & 740.8 & 308.7 & 0.63 \\
\hline Vitamin B12 (mg) & 4.85 & 2.8 & 5.43 & 4.5 & 4.78 & 3.2 & 5.02 & 3.6 & 0.31 \\
\hline Iron (mg) & 25.18 & 10.8 & 25.5 & 11.4 & 24.49 & 11.9 & 35 & 11.3 & 0.78 \\
\hline Zinc (mg) & 15.6 & 6.5 & 16.16 & 7 & 15 & 6.7 & 15.5 & 6.7 & 0.41 \\
\hline Selenium $(\mu \mathrm{g})$ & 160.74 & 81.2 & 171.35 & 91.8 & 165.18 & 90.6 & 165.7 & 87.9 & 0.64 \\
\hline Magnesium (mg) & 600.54 & 261.5 & 581.63 & 266.4 & 502.76 & 244.4 & 561.7 & 260.4 & 0.008 \\
\hline caffeine(mg) & 112.41 & 119 & 100.9 & 74.5 & 104.78 & 92 & 104.7 & 92 & 0.54 \\
\hline onion (g) & 16.55 & 17.1 & 16.38 & 18.5 & 16.25 & 22.1 & 16.3 & 19.3 & 0.99 \\
\hline Garlic (g) & 0.97 & 2.4 & 0.37 & 0.7 & 0.36 & 0.6 & 0.75 & 1.5 & 0.002 \\
\hline peeper $(g)$ & 17.66 & 25.2 & 12.2 & 18 & 8.8 & 14.6 & 12.8 & 20 & 0.002 \\
\hline Black Tea (g) & 449.68 & 515.4 & 406.91 & 339.4 & 412.38 & 361.5 & 422.9 & 412 & 0.68 \\
\hline Spices (g) & 2.85 & 2.6 & 2.81 & 2.8 & 3.1 & 2.8 & 2.9 & 2.8 & 0.7 \\
\hline
\end{tabular}

Comparisons of nutrient intake across the tertiles of the DII were analyzed using a one-way ANOVA.

* RE: retinol equivalent 
Table3. Body composition parameters according to Tertiles (T) of the DII.

\begin{tabular}{|c|c|c|c|c|c|c|c|c|c|c|}
\hline & \multirow{2}{*}{\multicolumn{2}{|c|}{$\begin{array}{c}\text { DII Score } \\
\text { Tertile1 }\end{array}$}} & \multirow{2}{*}{\multicolumn{2}{|c|}{$\begin{array}{c}\text { DII Score } \\
\text { Tertile2 }\end{array}$}} & \multirow{2}{*}{\multicolumn{2}{|c|}{$\begin{array}{c}\text { DII Score } \\
\text { Tertile3 } \\
\begin{array}{c}\left(1.73 \_4.15\right) \\
(\mathrm{n}=120)\end{array}\end{array}$}} & \multirow{2}{*}{\multicolumn{2}{|c|}{$\begin{array}{c}\text { All } \\
(\mathrm{n}=361)\end{array}$}} & \multirow{3}{*}{$\begin{array}{c}{ }^{*} \mathrm{P}- \\
\text { ANOVA }\end{array}$} & \multirow{3}{*}{ 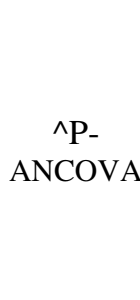 } \\
\hline & & & & & & & & & & \\
\hline & mean & SD & mean & SD & mean & SD & mean & $\mathrm{SD}$ & & \\
\hline Weight (kg) & 70.51 & 16.82 & 70.32 & 14.85 & 67.11 & 16 & 69.32 & 15.9 & 0.17 & 0.36 \\
\hline BMI (kg/m²) & 24.61 & 4.61 & 24.50 & 4.43 & 23.61 & 4.50 & 24.24 & 4.50 & 0.17 & 0.30 \\
\hline PFM (\%) & 30.19 & 9.62 & 29.77 & 10.74 & 29.19 & 10.51 & 29.72 & 10.2 & 0.75 & 0.58 \\
\hline PMM (\%) & 31.41 & 6.69 & 32.01 & 7.56 & 31.16 & 7.38 & 31.53 & 7.2 & 0.64 & 0.76 \\
\hline VFR & 5.74 & 3.45 & 5.31 & 3.01 & 5.03 & 3.32 & 5.36 & 3.2 & 0.23 & 0.35 \\
\hline WC (cm) & 81.84 & 12.87 & 81.83 & 11.33 & 80.47 & 12.20 & 81.3 & 12.1 & 0.60 & 0.89 \\
\hline WhtR & 0.48 & 0.06 & 0.48 & 0.07 & 0.47 & 0.06 & 0.48 & 0.06 & 0.76 & 0.83 \\
\hline
\end{tabular}

* ANOVA analysis across DII score tertiles; ^ ANCOVA analysis across DII score tertiles with adjustment for age, sex, energy intake

BMI: body mass index; FM: fat mass; PFM: percentage fat mass; FFM: fat free mass; VFR: visceral fat ratio, WC: Waist circumference and WhtR: Waist/Height Ratio

Table4. Standardized regression coefficients $(B)$ and confidence intervals $(95 \% \mathrm{Cl})$ and $\mathrm{P}$-trend of the association between DII score and anthropometric variables

\begin{tabular}{|c|c|c|c|c|c|}
\hline \multirow{2}{*}{\multicolumn{2}{|c|}{ Variables }} & $\begin{array}{c}\text { DII Score } \\
\text { Tertile3 } \\
\end{array}$ & $\begin{array}{c}\text { DII Score } \\
\text { Tertile2 }\end{array}$ & $\begin{array}{c}\text { DII Score } \\
\text { Tertile1 }\end{array}$ & \multirow{2}{*}{$\begin{array}{l}\mathrm{P}- \\
\text { trend }\end{array}$} \\
\hline & & $\begin{array}{c}\left(1.73 \_4.15\right) \\
(\mathrm{n}=120)\end{array}$ & $\begin{array}{c}\left(0.79 \_1.72\right) \\
(\mathrm{n}=121)\end{array}$ & $\begin{array}{c}\left(-2.22 \_0.78\right) \\
(\mathrm{n}=120)\end{array}$ & \\
\hline \multirow{2}{*}{$\begin{array}{c}\text { Weight } \\
(\mathbf{k g})\end{array}$} & $\mathrm{a}$ & 1 & $\begin{array}{c}3.2 \\
(-.79,7.20)\end{array}$ & $\begin{array}{c}3.39 \\
(-.61,7.40)\end{array}$ & 0.09 \\
\hline & b & 1 & $\begin{array}{c}1.38 \\
(-1.96,4.72) \\
\end{array}$ & $\begin{array}{c}1.68 \\
(-1.74,5.11) \\
\end{array}$ & 0.33 \\
\hline \multirow{2}{*}{$\begin{array}{l}\text { WC } \\
(\mathrm{cm})\end{array}$} & $\mathrm{a}$ & 1 & $\begin{array}{c}1.36 \\
(-1.69,4.41)\end{array}$ & $\begin{array}{c}1.37 \\
(-1.68,4.43)\end{array}$ & 0.37 \\
\hline & $\mathrm{b}$ & 1 & $\begin{array}{c}0.04 \\
(-2.47,2.55) \\
\end{array}$ & $\begin{array}{c}0.49 \\
(-2.08,3.07) \\
\end{array}$ & 0.7 \\
\hline \multirow{2}{*}{ WhtR } & $\mathrm{a}$ & 1 & $\begin{array}{c}0.002 \\
(-0.014,0.019)\end{array}$ & $\begin{array}{c}0.006 \\
(-0.011,0.02)\end{array}$ & 0.47 \\
\hline & $\mathrm{b}$ & 1 & $\begin{array}{c}-0.003 \\
(-0.019,0.013)\end{array}$ & $\begin{array}{c}0.003 \\
(-0.10,0.02) \\
\end{array}$ & 0.7 \\
\hline \multirow{2}{*}{$\begin{array}{c}\text { BMI } \\
\left(\mathbf{k g} / \mathbf{m}^{2}\right)\end{array}$} & $\mathrm{a}$ & 1 & $\begin{array}{c}0.88 \\
(-0.24,2.02)\end{array}$ & $\begin{array}{c}0.99 \\
(-0.14,2.13)\end{array}$ & 0.08 \\
\hline & b & 1 & $\begin{array}{c}0.6 \\
(-0.5,1.71) \\
\end{array}$ & $\begin{array}{c}0.24 \\
(-0.42,1.84) \\
\end{array}$ & 0.22 \\
\hline \multirow{2}{*}{$\begin{array}{c}\text { PMM } \\
(\%)\end{array}$} & $\mathrm{a}$ & 1 & $\begin{array}{c}0.85 \\
(-0.96,2.66)\end{array}$ & $\begin{array}{c}0.24 \\
(-1.57,3.59)\end{array}$ & 0.78 \\
\hline & b & 1 & 0.16 & -0.17 & 0.72 \\
\hline
\end{tabular}




\begin{tabular}{|c|c|c|c|c|c|}
\hline & & & $(-0.78,1.1)$ & $(-1.13,0.79)$ & \\
\hline \multirow{2}{*}{$\begin{array}{c}\text { PFM } \\
(\%)\end{array}$} & $\mathrm{a}$ & 1 & $\begin{array}{c}0.58 \\
(-2.00,3.17)\end{array}$ & $\begin{array}{c}1 \\
(-1.59,3.59)\end{array}$ & 0.45 \\
\hline & b & 1 & $\begin{array}{c}1.14 \\
(-0.91,3.19) \\
\end{array}$ & $\begin{array}{c}1.11 \\
(-0.99,3.22) \\
\end{array}$ & 0.29 \\
\hline \multirow{2}{*}{ VFR } & $\mathrm{a}$ & 1 & $\begin{array}{c}0.28 \\
(-0.53,1.11)\end{array}$ & $\begin{array}{c}0.71 \\
(-0.10,1.54)\end{array}$ & 0.08 \\
\hline & $\mathrm{b}$ & 1 & $\begin{array}{c}-0.06 \\
(-0.8,0.66)\end{array}$ & $\begin{array}{c}0.35 \\
(-0.39,1.11) \\
\end{array}$ & 0.35 \\
\hline
\end{tabular}

BMI: body mass index; FM: fat mass; PFM: percentage fat mass; FFM: fat free mass; VFR: visceral fat ratio, WC: Waist circumference and WhtR: Waist/Height Ratio

a Model 0, linear regression analysis without adjustment; b Model I, linear regression analysis with adjustment for age and sex; energy intake, physical activity, Educational level, Economic levels and supplements. 1: Tertile 3 was considered as a reference.

a Model 0, logistic regression analysis without adjustment; b Model I, logistic regression analysis with adjustment

Table5. Odd Ratio (OR) and confidence intervals $(95 \% \mathrm{Cl})$ and P-trend of the association between DII score and Obesity, Over Weight and Abdominal Obesity

\begin{tabular}{|c|c|c|c|c|c|c|}
\hline \multicolumn{2}{|l|}{ Variables } & \multirow{2}{*}{$\begin{array}{l}\text { DII Score Tertile3 } \\
\begin{array}{c}\left(1.73 \_4.15\right) \\
(\mathrm{n}=120)\end{array} \\
1\end{array}$} & \multirow{2}{*}{$\begin{array}{c}\text { DII Score Tertile2 } \\
\begin{array}{c}\left(0.79 \_1.72\right) \\
(\mathrm{n}=121)\end{array} \\
0.91 \\
(.38,2.16)\end{array}$} & \multirow{2}{*}{$\begin{array}{l}\text { DII Score Tertile1 } \\
\begin{array}{c}\left(-2.22 \_0.78\right) \\
(\mathrm{n}=120)\end{array} \\
1.11 \\
(.45,2.72)\end{array}$} & \multirow{2}{*}{$\begin{array}{c}\mathrm{P}- \\
\text { trend } \\
0.82\end{array}$} & \multirow{7}{*}{$\begin{array}{l}\text { Educational level, } \\
\text { Economic levels and } \\
\text { supplements } \\
\text { P-value for trend } \\
\text { determined by logistic } \\
\text { regression models. } 1 \text { : } \\
\text { Tertile } 3 \text { was } \\
\text { considered as a } \\
\text { reference. } \\
* \text { Abdominal Obesity: } \\
\text { waist circumference } \\
>102 \text { in male and } \\
\text { Waist circumference } \\
>88 \text { in female }\end{array}$} \\
\hline \multirow{2}{*}{$\begin{array}{l}\text { Abdominal } \\
\text { Obesity }\end{array}$} & $\mathrm{a}$ & & & & & \\
\hline & $\mathrm{b}$ & 1 & $\begin{array}{c}1.06 \\
(0.42,2.68) \\
\end{array}$ & $\begin{array}{c}1.26 \\
(.45,3.5)\end{array}$ & 0.66 & \\
\hline \multirow{2}{*}{$\begin{array}{c}\text { Obesity } \\
(\mathrm{BMI} \geq 30)\end{array}$} & $\mathrm{a}$ & 1 & $\begin{array}{c}1.51 \\
(0.67,3.4)\end{array}$ & $\begin{array}{c}1.2 \\
(0.51,2.8)\end{array}$ & 0.68 & \\
\hline & $\mathrm{b}$ & 1 & $\begin{array}{c}1.32 \\
(0.56,3.08) \\
\end{array}$ & $\begin{array}{c}1.17 \\
(0.46,2.95) \\
\end{array}$ & 0.73 & \\
\hline \multirow{2}{*}{$\begin{array}{c}\text { Over Weight } \\
(25 \leq \mathrm{BMI}<30)\end{array}$} & $\mathrm{a}$ & 1 & $\begin{array}{c}1.14 \\
(0.62,2.08)\end{array}$ & $\begin{array}{c}1.67 \\
(0.93,3.08)\end{array}$ & 0.07 & \\
\hline & $\mathrm{b}$ & 1 & $\begin{array}{c}1.16 \\
(0.62,2.17)\end{array}$ & $\begin{array}{c}1.6 \\
(0.9,3.08)\end{array}$ & 0.10 & \\
\hline
\end{tabular}

for age and sex; energy intake, physical activity, Educational level, Economic levels and P-value for trend determined by logistic Tertile 3 was reference.

* Abdominal Obesity: imference Waist circumference

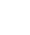




\section{REFERENCES}

1. Ruiz-Canela M, Zazpe I, Shivappa N, Hébert JR, Sanchez-Tainta A, Corella D, et al. Dietary inflammatory index and anthropometric measures of obesity in a population sample at high cardiovascular risk from the PREDIMED (PREvencion con DIeta MEDiterranea) trial. British journal of nutrition. 2015;01(6):984-95.

2. Salimi Y, Taghdir M, Sepandi M, Zarchi A-AK. The prevalence of overweight and obesity among Iranian military personnel: a systematic review and meta-analysis. BMC public health. 2019;02(1):162.

3. Azadbakht, Mirmiran, Shiva, Azizi. General obesity and central adiposity in a representative sample of Tehranian adults: prevalence and determinants. International journal for vitamin and nutrition research. 2005;03(4):297-304.

4. Kord Varkaneh H K V, Rahmani J, Tajik S, Zarezadeh M, Nazari A, Fatahi S. Association between dietary inflammatory index with obesity in Women who referred to health centers affiliated to Tehran University of Medical Sciences. RJMS. 2017; 24 (161) :21-30.

5 Mohajeri Tehrani M.R. Screening and clinical examination of obese patients. J Diabetes Metabol Disorders 2013;12(5):393-398.6. Benelli, R., et al., Cytokines and chemokines as regulators of angiogenesis in health and disease. Current pharmaceutical design, 2006. 09(24): p. 3101-3115.

6. Benelli R, Lorusso G, Albini A, Noonan D. Cytokines and chemokines as regulators of angiogenesis in health and disease. Current pharmaceutical design. 2006;09(24):3101-15.

7. Correa-Rodríguez M, Rueda-Medina B, González-Jiménez E, Correa-Bautista JE, Ramírez-Vélez R, Schmidt-RioValle J. Dietary inflammatory index, bone health and body composition in a population of young adults: a cross-sectional study. International journal of food sciences and nutrition. 2018;06:1-7.

8. Malshe SD, Udipi SA. Waist-to-Height Ratio in Indian Women: Comparison With Traditional Indices of Obesity, Association With Inflammatory Biomarkers and Lipid Profile. Asia Pacific Journal of Public Health. 2017;10(5):411-21.

9. Ramallal R, Toledo E, Martínez JA, Shivappa N, Hébert JR, Martínez-González MA, et al. Inflammatory potential of diet, weight gain, and incidence of overweight/obesity: the SUN cohort. Obesity. 2017;11(6):997-1005.

10. Estruch R, Martínez-González MA, Corella D, Salas-Salvadó J, Ruiz-Gutiérrez V, Covas MI, et al. Effects of a Mediterranean-style diet on cardiovascular risk factors: a randomized trial. Annals of internal medicine. 2006;12(1):1-11.

11. Johansson-Persson A, Ulmius M, Cloetens L, Karhu T, Herzig K-H, Önning G. A high intake of dietary fiber influences C-reactive protein and fibrinogen, but not glucose and lipid metabolism, in mildly hypercholesterolemic subjects. European journal of nutrition. 2014;13(1):39-48.

12. Richard C, Couture P, Desroches S, Lamarche B. Effect of the Mediterranean diet with and without weight loss on markers of inflammation in men with metabolic syndrome. Obesity. $2013 ; 14$

(1):51-7.

13. Shivappa N, Steck SE, Hurley TG, Hussey JR, Hébert JR. Designing and developing a literature-derived, population-based dietary inflammatory index. Public health nutrition. 2014;15(8):1689-96. 
14. Sokol A, Wirth MD, Manczuk M, Shivappa N, Zatonska K, Hurley TG, et al. Association between the dietary inflammatory index, waist-to-hip ratio and metabolic syndrome. Nutrition research. 2016;24(11):1298-303.

15. San KMM, Fahmida U, Wijaksono F, Lin H, Zaw KK, Htet MK. Chronic low grade inflammation measured by dietary inflammatory index and its association with obesity among school teachers in Yangon, Myanmar. Asia Pacific journal of clinical nutrition. 2018;29(1):92.

16. Alam I, Shivappa N, Hebert JR, Pawelec G, Larbi A. Relationships between the inflammatory potential of the diet, aging and anthropometric measurements in a cross-sectional study in Pakistan. Nutrition and healthy aging. 2018;30(4):335-43.

17. Kim Y, Chen J, Wirth MD, Shivappa N, Hebert JR. Lower dietary inflammatory index scores are associated with lower glycemic index scores among college students. Nutrients. 2018;40(2):182.

18. Esfahani FH, Asghari G, Mirmiran P, Azizi F. Reproducibility and relative validity of food group intake in a food frequency questionnaire developed for the Tehran Lipid and Glucose Study. Journal of epidemiology. 2010;35(2):150-8.

19. Alidadi Y, Metanati M, Ataie-Jafari A. Thevalidity of a bioelectrical impedance analyzer, Xiaomi MI scale 2, for measurement of body composition. Age (yr). 2019;28(9.1):30.4-9.4.

20. Moghaddam MB, Aghdam FB, Jafarabadi MA, Allahverdipour H, Nikookheslat SD, Safarpour S. The Iranian Version of International Physical Activity Questionnaire (IPAQ) in Iran: content and construct validity, factor structure, internal consistency and stability. World Appl Sci. 2012;34(8):1073-80.

21. Farhangi MA, Najafi M. Dietary inflammatory index: a potent association with cardiovascular risk factors among patients candidate for coronary artery bypass grafting (CABG) surgery. Nutrition journal. 2018;36(1):20.

22. Shivappa N, Bonaccio M, Hebert JR, Di Castelnuovo A, Costanzo S, Ruggiero E, et al. Association of proinflammatory diet with low-grade inflammation: results from the Moli-sani study. Nutrition. 2018;37:182-8.

23. Wirth MD, Shivappa N, Davis L, Hurley TG, Ortaglia A, Drayton R, et al. Construct validation of the dietary inflammatory index among African Americans. The journal of nutrition, health \& aging. 2017;38(5):487-91.

24. Oliveira TMS, Bressan J, Pimenta AM, Martínez-González M-Á, Shivappa N, Hébert JR, et al. Dietary inflammatory index and prevalence of overweight and obesity in Brazilian graduates from the Cohort of Universities of Minas Gerais (CUME project). Nutrition. 2020;32:110635.

25. Mazidi M, Shivappa N, Wirth MD, Hebert JR, Mikhailidis DP, Kengne AP, et al. Dietary inflammatory index and cardiometabolic risk in US adults. Atherosclerosis. 2018;39:23-7.

26. Ren Z, Zhao A, Wang Y, Meng L, Szeto IM-Y, Li T, et al. Association between dietary inflammatory index, C-reactive protein and metabolic syndrome: a cross-sectional study. Nutrients. 2018;40

(7):831.

27. Shivappa N, Hebert JR, Marcos A, Diaz LE, Gomez S, Nova E, et al. Association between dietary inflammatory index and inflammatory markers in the HELENA study. Molecular nutrition \& food research. 2017;61(6):1600707.

28. Nikniaz L, Nikniaz Z, Shivappa N, Hébert JR. The association between dietary inflammatory index and metabolic syndrome components in Iranian adults. Primary care diabetes. 2018;43(5):467-72. 
29. Muhammad HFL, van Baak MA, Mariman EC, Sulistyoningrum DC, Huriyati E, Lee YY, et al. Dietary inflammatory index score and its association with body weight, blood pressure, lipid profile, and leptin in Indonesian adults. Nutrients. 2019;44(1):148.

30. Camargo-Ramos CM, Correa-Bautista JE, Correa-Rodríguez M, Ramírez-Vélez R. Dietary inflammatory index and cardiometabolic risk parameters in overweight and sedentary subjects. International journal of environmental research and public health. 2017;6a(10):1104.

31. Vahid F, Bourbour F, Gholamalizadeh M, Shivappa N, Hébert JR, Babakhani K, et al. A pro-inflammatory diet increases the likelihood of obesity and overweight in adolescent boys: a case-control study. Diabetology \& Metabolic Syndrome. 2020;12:1-8.

32. Sethna CB, Alanko D, Wirth MD, Shivappa N, Hebert JR, Khan S, et al. Dietary inflammation and cardiometabolic health in adolescents. Pediatric Obesity. 2020:e12706.

33. Mazidi M, Shivappa N, Wirth MD, Hebert JR, Mikhailidis DP, Kengne AP, et al. Dietary inflammatory index and cardiometabolic risk in US adults. Atherosclerosis. 2018;276:23-7. 